\title{
Mechanisms and Evidence of Genital Coevolution: The Roles of Natural Selection, Mate Choice, and Sexual Conflict
}

\author{
Patricia L.R. Brennan ${ }^{1,2}$ and Richard O. Prum ${ }^{3}$ \\ ${ }^{1}$ Departments of Psychology and Biology, University of Massachusetts, Amherst, MA 01003 \\ ${ }^{2}$ Organismic and Evolutionary Biology Graduate Program, University of Massachusetts, Amherst, MA 01003 \\ ${ }^{3}$ Department of Ecology and Evolutionary Biology and Peabody Museum of Natural History, \\ Yale University, New Haven, CT 06520 \\ Correspondence: pbrennan@cns.umass.edu
}

Genital coevolution between the sexes is expected to be common because of the direct interaction between male and female genitalia during copulation. Here we review the diverse mechanisms of genital coevolution that include natural selection, female mate choice, male-male competition, and how their interactions generate sexual conflict that can lead to sexually antagonistic coevolution. Natural selection on genital morphology will result in size coevolution to allow for copulation to be mechanically possible, even as other features of genitalia may reflect the action of other mechanisms of selection. Genital coevolution is explicitly predicted by at least three mechanisms of genital evolution: lock and key to prevent hybridization, female choice, and sexual conflict. Although some good examples exist in support of each of these mechanisms, more data on quantitative female genital variation and studies of functional morphology during copulation are needed to understand more general patterns. A combination of different approaches is required to continue to advance our understanding of genital coevolution. Knowledge of the ecology and behavior of the studied species combined with functional morphology, quantitative morphological tools, experimental manipulation, and experimental evolution have been provided in the best-studied species, all of which are invertebrates. Therefore, attention to vertebrates in any of these areas is badly needed.

$\mathrm{O}$ all the evolutionary interactions between the sexes, the mechanical interaction of genitalia during copulation in species with internal fertilization is perhaps the most direct. For this reason alone, coevolution between genital morphologies of males and females is expected. Morphological and genetic components of male and female genitalia have been shown to covary in many taxa (Sota and Kubota 1998; Ilango and Lane 2000; Arnqvist and Rowe 2002; Brennan et al. 2007; Rönn et al. 2007; Kuntner et al. 2009; Tatarnic and Cassis 2010; Cayetano et al. 2011; Evans et al. 2011, 2013; Simmons and García-González 2011; Yassin and Orgogozo 2013; and see examples in Table 1).

Editors: William R. Rice and Sergey Gavrilets

Additional Perspectives on The Genetics and Biology of Sexual Conflict available at www.cshperspectives.org

Copyright (C) 2015 Cold Spring Harbor Laboratory Press; all rights reserved; doi: 10.1101/cshperspect.a017749

Cite this article as Cold Spring Harb Perspect Biol 2015;7:a017749 
P.L.R. Brennan and R.O. Prum
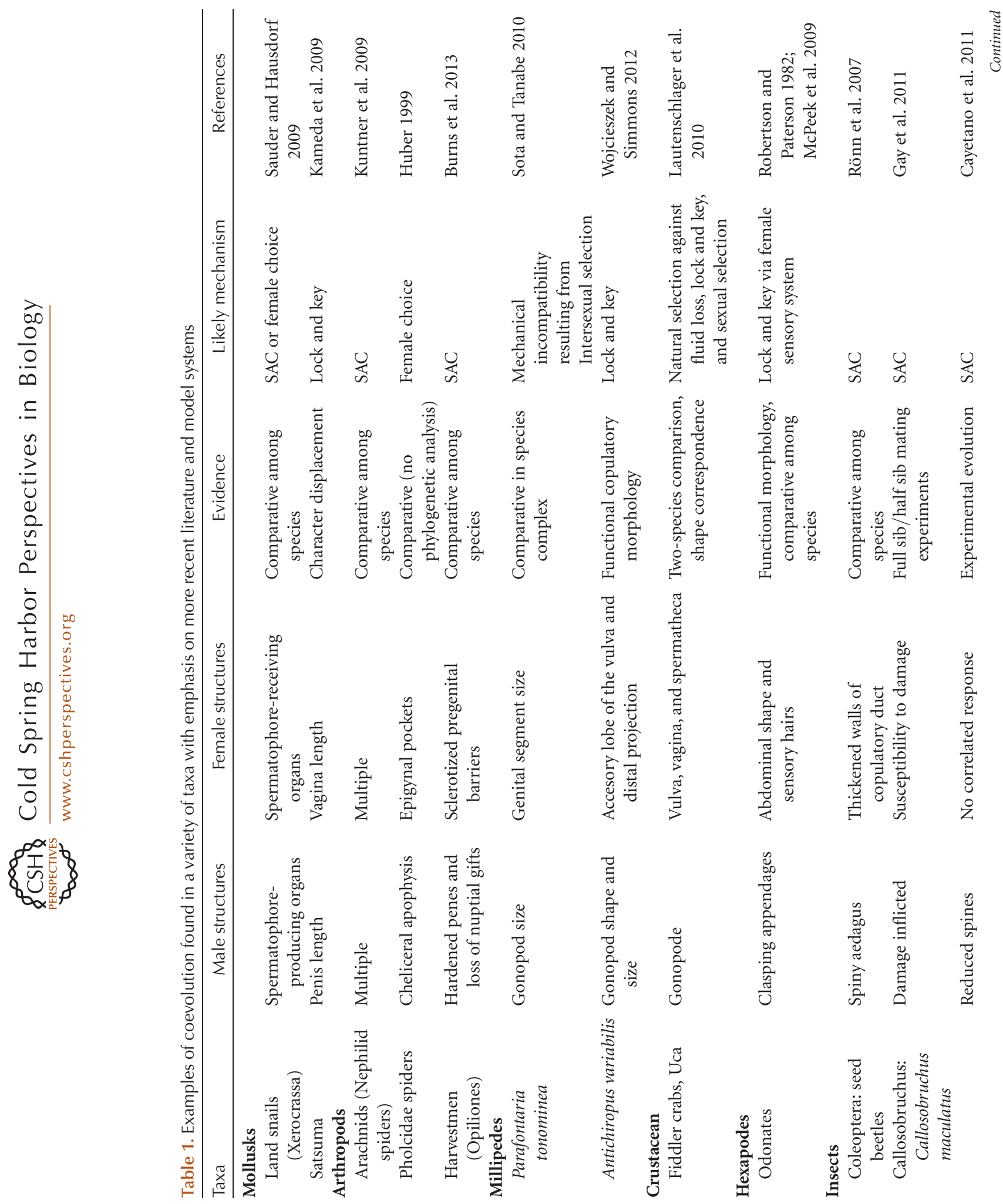
Mechanisms of Genital Coevolution
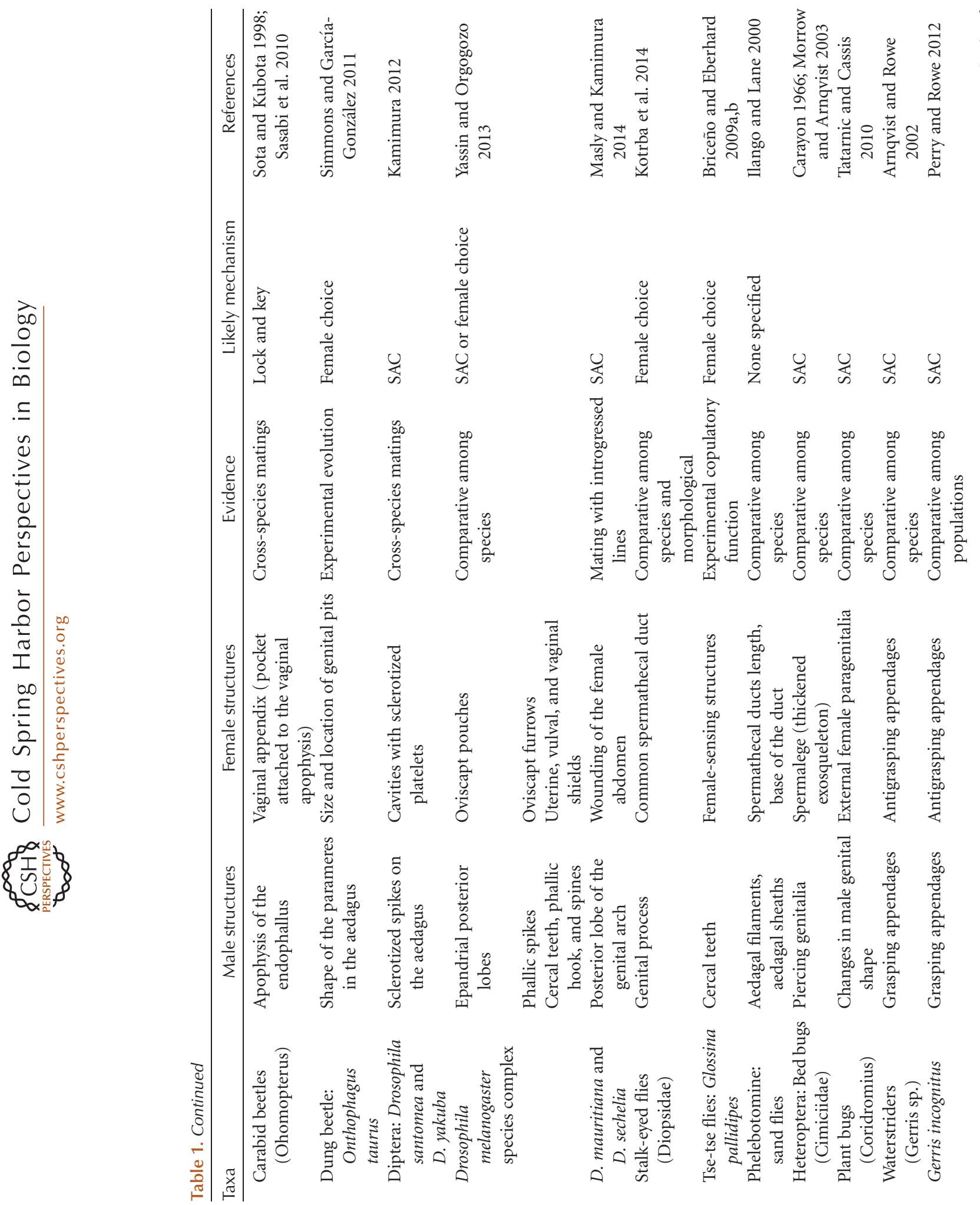
P.L.R. Brennan and R.O. Prum
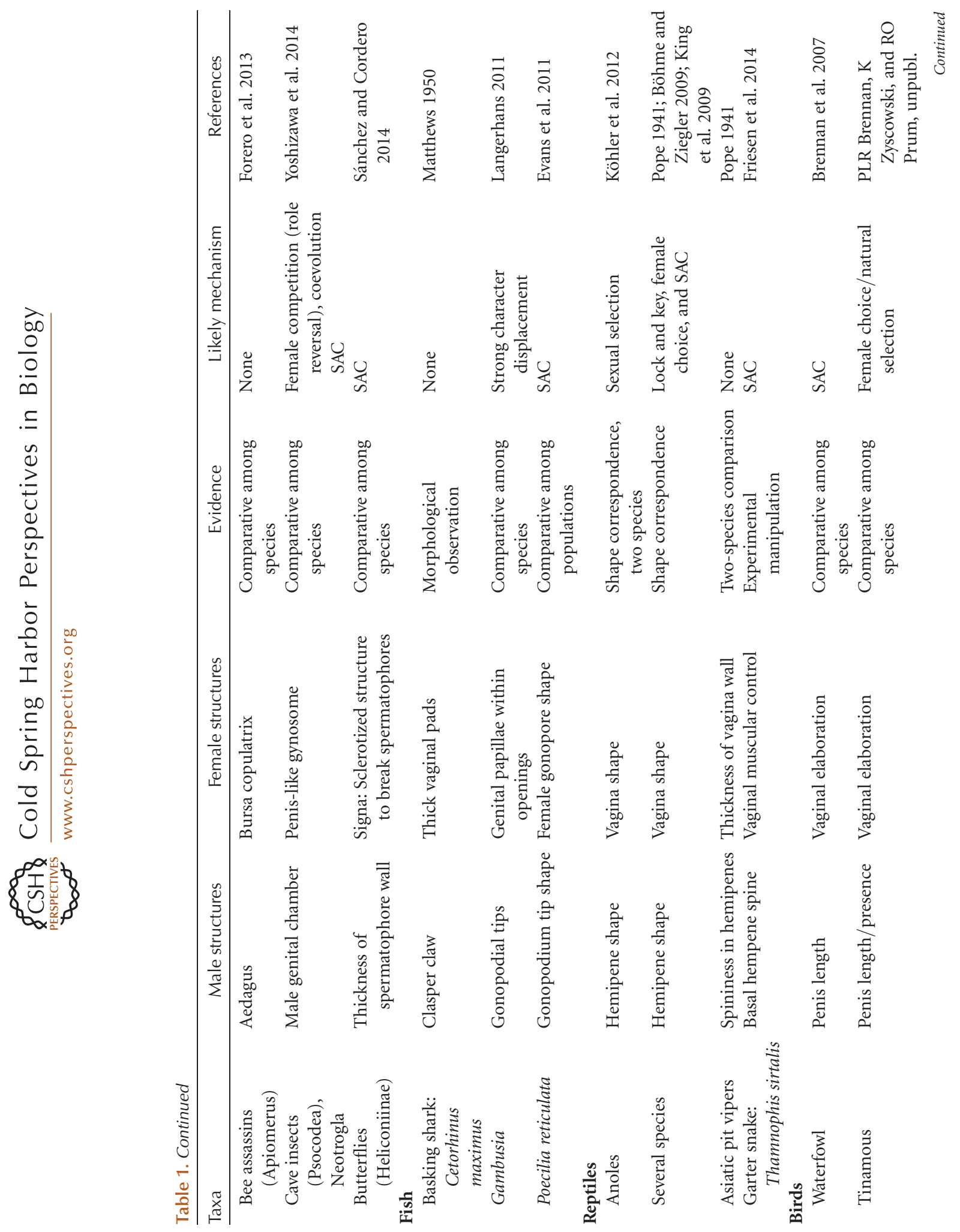
Mechanisms of Genital Coevolution
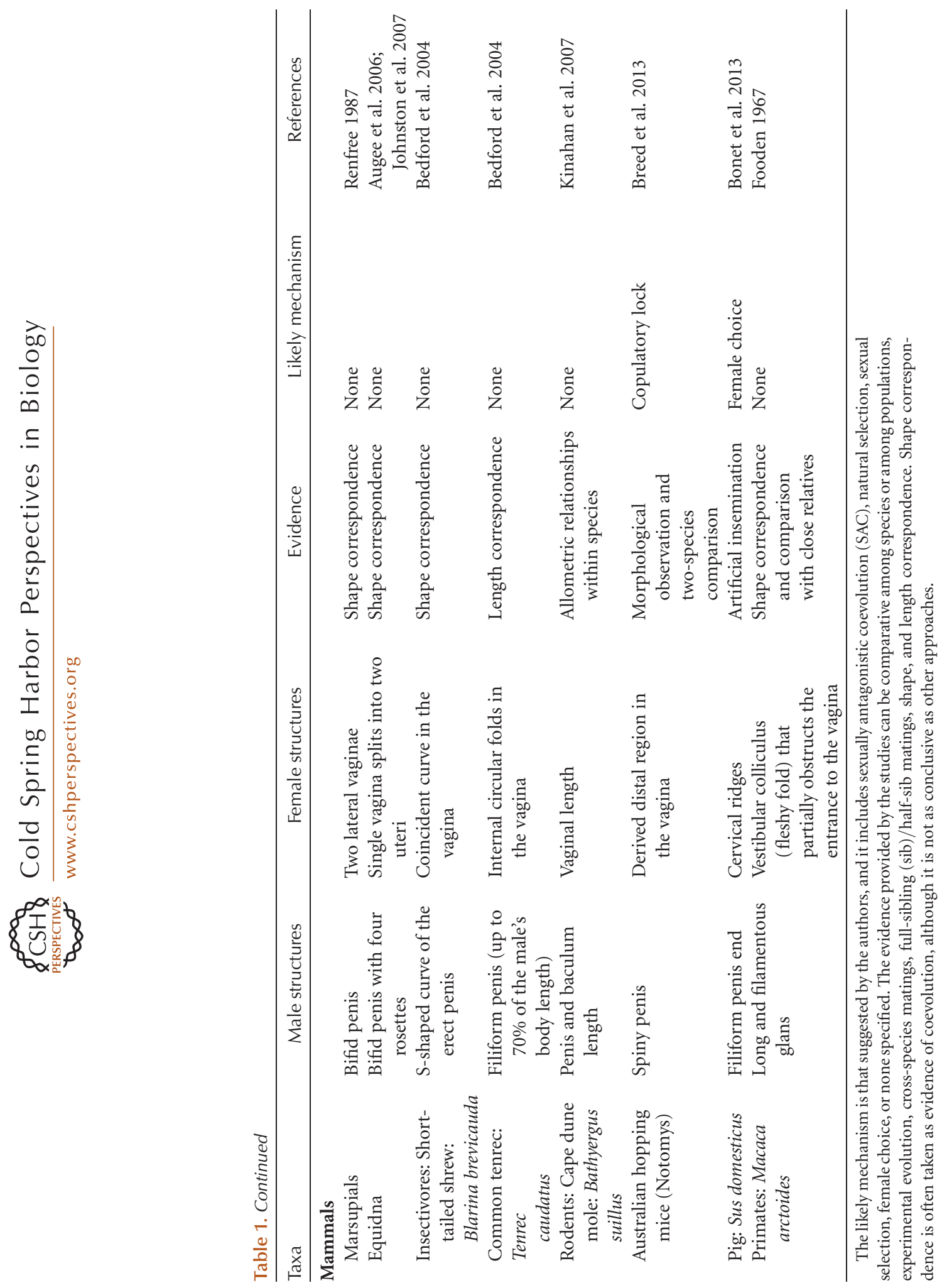
Male genitalia are among the most variable structures in nature (Eberhard 1985). In contrast, female genitalia have typically been found not to be as interspecifically variable as male genitalia in several studies that specifically examined and described them (Eberhard 1985, 2010a,b). Female genitalia are not studied as often as male genitalia, perhaps because of a male-biased view of evolutionary processes by researchers (Ah-King et al. 2014). However, studying female genitalia is undeniably challenging. Male genitalia are generally kept inside of the body cavity, but are everted before, or during copulation, so their functional morphology can be more easily studied than the internal genitalia of females. Female genitalia also tend to be softer than male genitalia and thus their morphology may be more difficult to describe, and can more easily be distorted on dissection and preservation. Female adaptations to sense or oppose features of male genitalia can be subtle, requiring careful study. Female genital tracts are under multiple sources of selection: not just mating, but also storing sperm, egg laying, birthing, and often interfacing with the terminal portion of the digestive tract. Therefore, selection balancing multiple functions may further constrain morphological evolution in female genitalia. However, even small morphological changes in female genitalia, for example, increases in vaginal muscle, may change a female's ability to choose or reject a male during mating, or to manage the costs of mating. Thus, the functional consequences to male and female genital morphology are hard to predict unless one knows how genitalia function during intromission. Despite these challenges, recent studies have examined variation of female genitalia and evidence is accumulating that features of female genitalia are variable enough to support coevolutionary processes (Polihronakis 2006; Puniamoorthy et al. 2010; Siegel et al. 2011; Showalter et al. 2013; and see additional references in Ah-King et al. 2014).

In this article, we will discuss different hypotheses of genital evolution that predict coevolution; however, this is not a review of that entire subject (but see Eberhard et al. 2010b; Simmons 2013). Rather, we discuss the various mecha- nisms of genital coevolution differentiating the potentially independent or overlapping roles of natural selection, female choice, and malemale competition (Fig. 1). This classification allows us to distinguish specifically those mechanisms of genital coevolution that involve sexual conflict (i.e., when the evolutionary interests of individuals of different sexes, particularly over mating, are different). We then highlight examples in different taxa organisms with particular emphasis on those that provide evidence of sexual conflict.

\section{GENITAL COEVOLUTION}

Genital coevolution results when evolutionary changes in a genital trait found in one sex selects for an evolutionary change in a genital trait

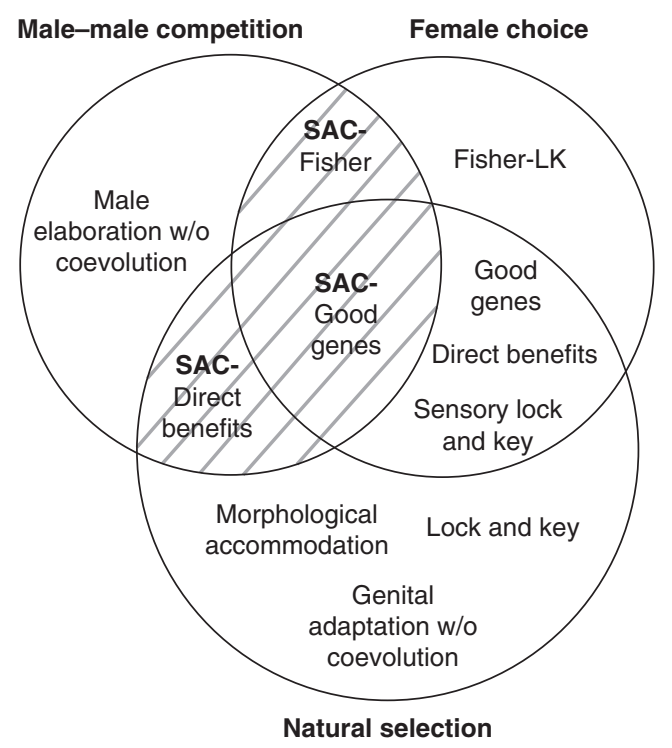

Figure 1. Graphical classification of mechanisms of genital evolution and coevolution. Three circles depict the independent and co-occurring actions of natural selection, female choice, and male-male competition. Different specific versions of genital coevolution can occur depending on which of the three broader evolutionary mechanisms are occurring. Sexual conflict (hatched lines) occurs through the simultaneous action of male-male competition and female choice, or male-male competition and natural selection. SAC, sexually antagonistic coevolution. See text for explanation. 
in the other sex. This reciprocal evolutionary change can be shown by both macroevolutionary and microevolutionary research approaches. Comparative studies of species and/or populations can provide evidence of dynamic changes in genital morphology in both sexes. These include investigations of morphological correspondence, compatibility in overall shape, or between morphological structures and corresponding sensing structures. Comparative studies can reveal evidence of arms races in which evolutionary changes in genital morphology of each sex are antagonistic. A microevolutionary approach can include studies of correlation between genital features (both correspondence or antagonistic), experimental manipulation to measure the fitness consequences of changes in genital morphology in both sexes, and most recently, experimental evolutionary approaches that directly inform on the selective pressures that act on genital features, and the presence of coevolutionary changes in both sexes. In Table 1 we summarize examples of systems in which all these diverse types of evidence for coevolution have been reported, and some of them we will discuss in detail.

As our examples outline below, many different genital traits may coevolve, including overall size, shape, functional morphology, size and shape of particular components of the genitalia including but not limited to spines, ridges, flaps, and many other superficial elaborations, nongenital contact structures, and physiology of moveable and erectile and inflatable components of genitalia known in vertebrates and invertebrates.

\section{MECHANISMS OF GENITAL COEVOLUTION}

Genital diversification has been hypothesized to result from pleitropy, and natural, sexual (Eberhard 1985; Hosken and Stockley 2004), and social selection (East et al. 1993). Within sexual selection, male-male competition, female choice, and sexual conflict can influence genital morphology. Some of these hypotheses predict genital coevolution between the sexes including natural selection for mechanically feasible copulation, lock and key to prevent hybridizations, female choice of preferred males, and sexually antagonistic coevolution resulting from sexual conflict. Neither pleiotropy, social signaling, or male-male competition explicitly predict coevolution, although changes brought on by these processes may elicit a coevolutionary response on females through a different mechanism.

Here, we discuss mechanisms of genital coevolution in terms of the independent or overlapping forces of natural selection, female choice, and male-male competition (Fig. 1). We identify those examples of sexually antagonistic coevolution between male and female genitalia as the result of the co-occurrence of female choice and male-male competition, or male-male competition and natural selection.

\section{Natural Selection}

\section{For Mechanically Feasible Copulation}

Natural selection to make copulation functionally possible must always influence genital morphology to achieve the basic function of gamete transfer (Darwin 1871), despite the likely action of other mechanisms in genital elaboration. This process can give rise to a pattern of morphological accommodation (Fig. 1). Genital size is of primary importance in the mechanical interaction during copulation, and therefore genital size covariation indicative of coevolution is likely to be important and widespread. Although size coevolution can also result from sexual selection, natural selection on genitalia to insure successful gamete transfer can help to explain many observed patterns, yet it is rarely discussed (Pereti 2010).

Three lines of evidence suggest that genital size fit is important. First, crossings between species with different genital sizes are almost always impossible or lethal to females, especially when males are much larger (Masly 2012). Second, when size dimorphism is marked, selection can operate to match genital size. In orbweaving spiders with extreme size dimorphism, tiny males have disproportionally large genitalia (up to $20 \%$ of their body mass) to match female genital size (Ramos et al. 2005). This has not been examined when males are larger than fe- 
males, but females may be predicted to enlarge their genitalia to accommodate large male genitalia (Langerhans 2011). Third, changes in genital size appear to be more constrained than changes in shape. In the Onthophagus beetles, the shape of male and female genitalia changes more rapidly than size (Macagno et al. 2011). This pattern was also shown in a study of experimental evolution of male genitalia in Onthophagus taurus, in which shape but not size of the aedeagus changed after 19 generations (Simmons et al. 2009), and in an experimental evolution study in mice Mus musculus, in which baculum width but not length was shown to change after 27 generations (Simmons and Firman 2014). However, an experimental evolution study of genitalia in Drosophila found that both size and shape of the genital arch changed in response to natural and sexual selection (House et al. 2013), so this pattern is not universal. However, male insects tend to show a pattern of negative allometry that suggests that genital size changes little relative to body size compared to other nongenital characters (Eberhard et al. 1998).

\section{For a Lock-and-Key Mechanism to Prevent Hybridization}

Defour noted that male genitalia in insects were often species specific and stated that these served to preserve "types" (Defour 1844). The "lock-and-key" hypothesis proposes that variation in genital form coevolves through natural selection against hybridization and to enhance reproductive isolation (Eberhard 1985; Shapiro and Porter 1989). Females avoid the fitness costs of having their eggs fertilized by a male of the wrong species by evolving genitalia that permit only males with the right fit to achieve mechanical coupling leading to fertilization. The male "key" must fit the female "lock." As such, this hypothesis predicts close coevolution in genital shape and mechanical fit during copulation. Shapiro and Porter (1989) provide an excellent review of the history, tests and evidence for and against this hypothesis in the insects. They conclude that although there is no evidence that lock and key explains most instances of genital elaboration in insects, the hypothesis has not really been falsified. A more recent review centers on examining hybridization between species, in which genital morphology seems to play a role in reproductive isolation via mechanical incompatibility (Masly 2012). Lock and key is supported by recent studies of millipede genitalia (e.g., Tanabe and Sota 2008; Wojcieszek and Simmons 2012, 2013).

There are several predictions of the lockand-key hypothesis that have not been supported (reviewed by Eberhard 1985, 2010a,b; Shapiro and Porter 1989), but they may simply not have been adequately tested (Simmons 2013). According to lock and key, matings between sympatric species should be mechanically difficult, and often this is not true. However, in two closely related sympatric Carabid beetles, interspecific mating are costly for both males and females and result in genital damage owing to mechanical mismatch (Sota and Kubota 1998). Further, genital divergence should be correlated with low hybrid fitness, otherwise selection would be too weak to drive further mechanical isolation; but again there is little evidence for this, an exception being the hybrid zone between the beetles described above, in which females have deformed ovaries (Sota and Kubota 1998). Because lock and key is based on natural selection for reinforcement of species isolation, there should also be character displacement in male genitalia of sister species in zones of sympatry compared to allopatry. Although Eberhard (2010b) argues that this has not been shown, Simmons (2013) details some insect examples in which reinforcement has been shown. Character displacement is involved in genital diversification and coevolution of penis and vagina length in land snails (Kameda et al. 2009), and in male and female genital diversification in fish of the genus Gambusia (Langerhans 2011). Finally, the most widespread reason why lock and key is deemed unlikely is the perception that female genitalia are not as variable as male's, that is, the keys are variable, but the locks are not (Eberhard 1985). However, examination of current literature suggests that this conclusion is only weakly supported even in the well-studied insects (Simmons 2013). 
Surprisingly, many studies of the lock-andkey mechanism do not examine females at all (e.g., Mutanen et al. 2006; and see references in Ah-King et al. 2014). Some studies also conclude that females are not variable by using either linear estimates of genital size or qualitative examinations of genital shape (Eberhard 2004a,b, 2006, 2010a,b). However, linear estimates do not capture the complexity of genital shape, and size may be selected to be less variable than shape as discussed above. When quantitative measures and ultrastructure analyses of female morphology and shape are conducted, significant genital morphological variation across species has been detected. For example, female genitalia in Drosophila were deemed to be fairly invariant across species (Eberhard and Ramirez 2004; Jagadeeshan and Singh 2006), but a recent study showed that in nine species of Drosophila, several aspects of female genital morphology covary with male genital traits (Fig. 2) (Yassin and Orgogozo 2013). A geometric morphometric analysis of genital shape among two sister species of water snakes (Nerodia sp.) that seemed very similar on visual examination alone, showed that vaginal shape of these two species differed significantly in the degree of bifurcation and the aspect ratio of the vagina (Showalter et al. 2013).

Although there are good reasons to suggest that lock and key is unlikely to explain widespread patterns of genital evolution, quantitative examination of female genitalia should be performed before ruling out the lock-and-key hypothesis on the basis of lack of female genital variation alone. Simmons (2013) has made a similar point.

Although evidence for genital covariation in shape has been used as evidence to support lock-and-key (e.g., Mikkola 1992), mechanically feasible copulation, female choice and sexually antagonistic coevolution can also result in shape coevolution. Therefore, genital coevolution is not an exclusive prediction of lock and key.

\section{Female Choice}

Female choice can result in coevolution of different features of genitalia. Just like any other sensory mediated mate choice mechanism, females may be able to use sensory stimuli received during copulation from male genitals as the basis for female choice. This process requires female to receive and evaluate these stimuli. Thus, if males stimulate females with vibrissae, then females must have the ability to contact the vibrissae and detect their movement, shape, or whatever component of male morphology is speculated to stimulate them.

Through sexual selection, mating preferences can coevolve with male traits through either the arbitrary Fisherian mechanism, or by adaptive good genes and direct benefits mechanisms (Fig. 1) (Kirkpatrick and Ryan 1991; Andersson 1994; Prum 2010). Female mate choice can affect male genital evolution when females choose on the basis of interaction with male genitalia
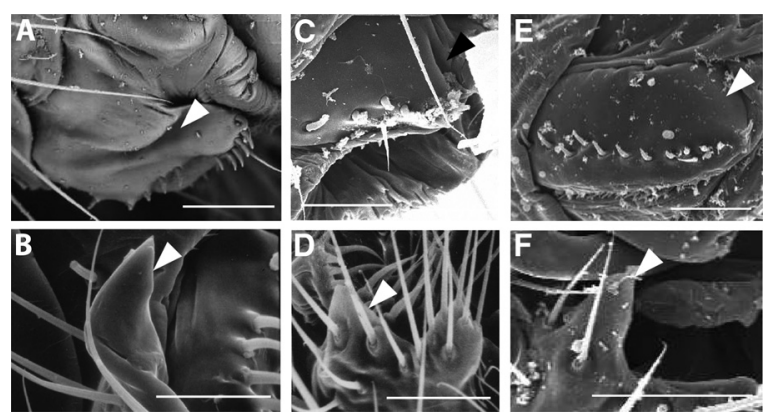

Figure 2. Female genitalia in Drosophila were previously thought to be invariant, but recent work has described extensive variation and coevolution in genital morphology. $(A, C, E)$ Female oviscapts, and $(B, D, F)$ male epandrial posterior lobes. Scale bars, $50 \mu \mathrm{m}$. (Reprinted from Yassin and Orgogozo 2013.) 
(Eberhard 1996). Thus, male and female genitalia may participate in all the same coevolutionary processes that characterize mating preferences and displays that are mediated by the sensory system during precopulatory interactions. Genital coevolution by female choice requires female promiscuity, so that females can choose among multiple males with whom they mate.

Female mate choice could result in arbitrary "Fisherian," or Lande Kirkpatrick (LK), coevolution in male and female genitalia via either sensory preferences or other anatomical features of female genitalia that allow females to evaluate male features. We discuss this possibility below in birds. As proposed for mate choice in general (Prum 2010), the arbitrary female choice mechanism is actually the null hypothesis of coevolution until evidence of good genes or direct benefits mechanisms can be obtained (Prum 2010). This process can occur when female mating preferences are not under natural selection.

The best support for genitally mediated female mate choice is provided by a series of experiments examining interactions between genital features of males, and female receptors in tsetse fly Glossina pallidipes. Modifications of the cercal teeth-the part of the male genitalia that squeezes the female abdomen—resulted in reduction of female sperm storage and ovulation while increasing remating probability. These changes were shown to be dependent on female structures the sense male stimulation (Briceño and Eberhard 2009a,b).

Studies of domestic pig (Sus domesticus) provide an example of genital coevolution via female choice in vertebrates. Male pigs have penises that end on a corkscrew filament whereas sows have ridges on their cervix that specifically sense stimulation from the penis during copulation. When sows are artificially inseminated, stimulation of the cervix ridges must occur otherwise the pregnancy rates drop dramatically (Bonet et al. 2013). This is consistent with a role for female choice in shaping pig penis morphology, although no information on male variation of genital features is available to determine its potential correlation with fertilization success. Many other mammals have these fila- mentous or finger-like endings on their penis (Eberhard 1985), suggesting that female choice may play an important role in shaping this particular class of genital elaboration.

A modified version of mechanical lock and key is known as the sensory lock and key; this hypothesis argues that differences in genital morphology perceived by either sex during copulation can result in premature termination of mating (Eberhard 1985, 2010a,b). Coevolution occurs between components of genitalia associated with sensing "fit," rather than purely mechanical aspects of shape differences that make copulation difficult. However, if mating success is mediated by female sensory perception, then this mechanism is essentially a form of female choice in which female mating preferences are under natural selection against hybridization (Fig. 1). Simmons (2013) argued that sensory lock and key is another type of female choice process that should be viewed as a continuum that enhances species isolation in one end, or that select for male features that increase female fitness on the other. Sensory lock and key to avoid hybridization is supported in some Odonates, in which mechanical isolation via clasping appendages is reported, and coevolution between the male abdominal claspers and female shape, sensory hairs (Robertson and Paterson 1982), and shape of female abdomens (McPeek et al. 2009) prevents heterospecific matings.

\section{Sexually Antagonistic Coevolution Resulting} from Sexual Conflict

So far we have discussed cases in which coevolution results in correspondence or fit. However, sexually antagonistic coevolution (SAC) that occurs as a consequence of sexual conflict between males and females can result in coevolutionary processes that reduce fit, or that function to decrease ease of copulation, or to mitigate male damage to the female. SAC occurs when genital adaptations coevolve in each sex to advance control over mating and fertilization initiating a coevolutionary arms race (Chapman et al. 2003; Parker 2006; Brennan and Prum 2012). Both direct and indirect selection are important in shaping evolutionary responses to 
sexual conflict including conflict over mating, fertilization, and mate identity (Arnqvist and Rowe 2005; Parker 2006; Brennan and Prum 2012). Thus, sexually antagonistic coevolution can proceed through either: (1) a combination of male-male competition for fertilization success and natural selection on female behavior, physiology or morphology to reduce the direct harm of sexual coercion (Arnqvist and Rowe 2005); or (2) a combination of male-male competition and female mate choice to maintain the indirect and direct benefits of choice (Fig. 1) (Parker 2006; Brennan and Prum 2012).

Waterstriders are a well-known example of sexually antagonistic coevolution to reduce direct costs (Arnqvist and Rowe 2002, 2005). Males jump on the back of the female to mate, and they remain attached to her as a form of mate guarding after copulation has taken place. Optimal female mating rate is lower in females than males, as females suffer mating costs from carrying males on their backs. As a result, conflict over mating frequency is strong. Comparative studies have shown that grasping devices in the legs of males that allow them to remain attached to females despite their struggles have coevolved with female antigrasping devices (Arnqvist and Rowe 2002).

Waterfowl are the best-known example of antagonistic genital coevolution in vertebrates. Males have corkscrew penises and penis length is correlated with the frequency of forced extrapair copulations (FEPCs) among species. FEPCs are costly to females, and they detract from otherwise female autonomous precopulatory mate preference. Females have evolved convoluted vaginas that make it difficult for unwanted males to evert their penis fully inside the female when they coerce a mating (Fig. 3A) (Brennan et al. 2007, 2010; Brennan and Prum 2012). Brennan and Prum (2012) hypothesize that female genital resistance morphologies in ducks have evolved through the indirect, genetic benefit of being fertilized by preferred males. Females that can prevent forced fertilizations will have offspring that inherit the male traits that they and other females prefer.

Genital coevolution in waterfowl has been dynamic, both increasing and decreasing in genital length and complexity during evolutionary history (Brennan et al. 2007). FEPCs can be up to $40 \%$ of all observed copulations, but only $2 \%-5 \%$ of offspring are sired as a result of unwanted matings. This is likely a combination of the success of female genital elaborations in excluding male penises from everting, as well as strategies for paternity protection pursued by the females' mate, who usually mates with the female immediately after FEPCs have occurred (Brennan and Prum 2012). Ducks also have evolved an explosive eversion mechanism that allows males to quickly inseminate females despite their resistance (Brennan et al. 2010). Female ducks have evolved thickened walls in the proximal end of their vagina presumably to be able to withstand the forces involved with penis eversion (PLR Brennan, K Zyscowski, and RO Prum, unpubl.).

In some cases, coevolved female morphological responses to sexual conflict are easily noticed as in the examples above. However, females can adapt in more subtle ways if behavioral, physiological, or minor morphological modifications are sufficient to allow them to mitigate male inflicted damage, or to assert control over fertilization and mate identity. For example, in red-sided garter snakes (Thamnophis sirtalis sirtalis), females exert some physiological control over copulation duration; experimental anesthesia of the female vagina dramatically increased copulation duration (Friesen et al. 2014). Conflict over copulation duration in garter snakes has likely resulted in modification and elaboration of male hemipene spines that allow males to stay attached to females for longer than optimal, as males with clipped spines stayed in copulo for a shorter period of time than intact males (Friesen et al. 2014). Copulation duration results from an interplay between male hemipene spines and female capacity to terminate copulation by contracting her vaginal musculature (Friesen et al. 2014). This example highlights that the lack of overt specialized female structures that function to prevent male access cannot be used as evidence against the role of sexual conflict in genital evolution (contra Eberhard 2004, 2006, 2010b). Female physiological and behavioral re- 
P.L.R. Brennan and R.O. Prum
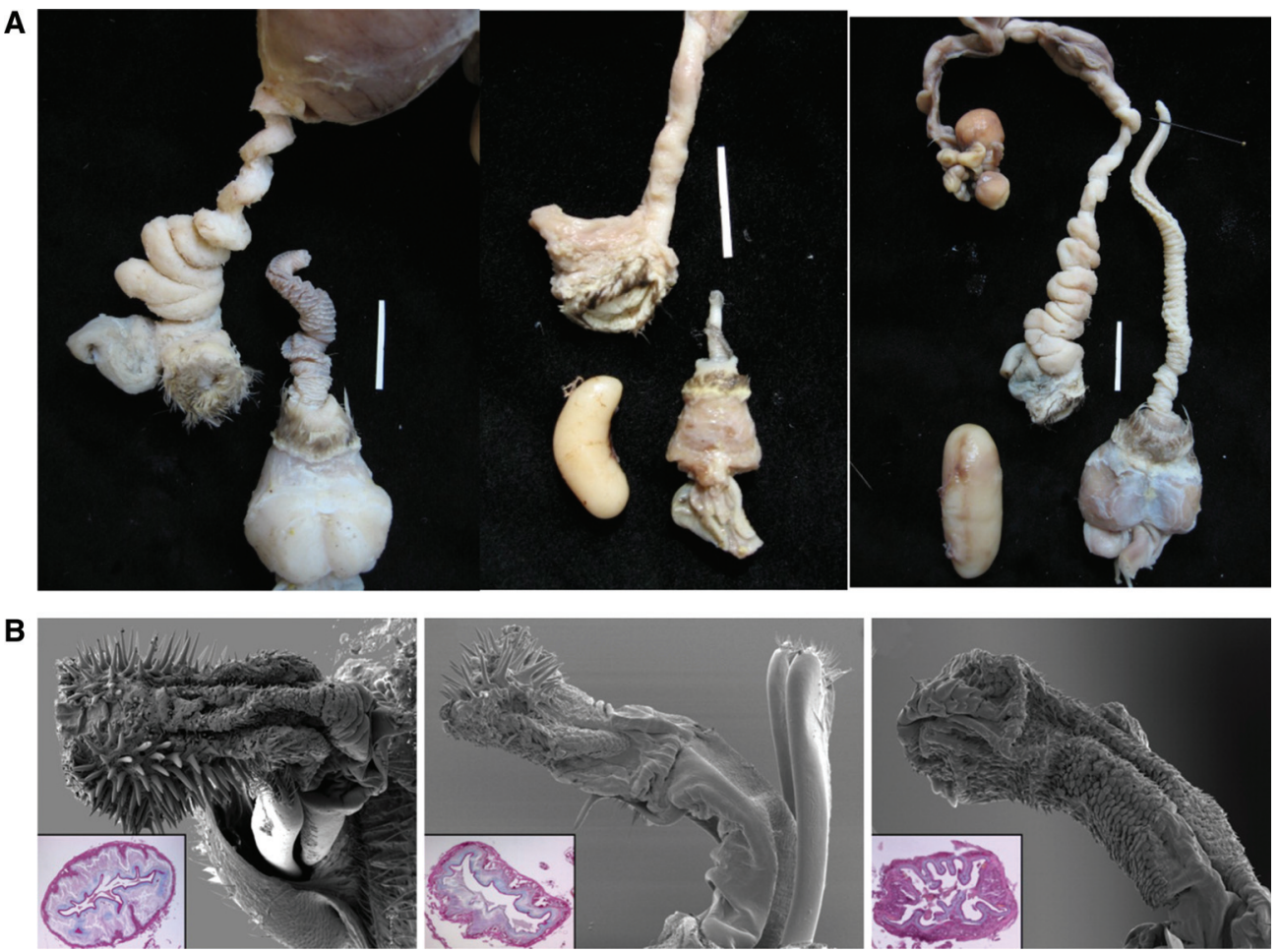

Figure 3. Genital coevolution via sexual conflict. $(A)$ Waterfowl, in which the elaboration of the vagina correlates with penis length (vagina on the left, penis on the right in mallard, harlequin, and long-tailed duck) Scale bars, 2 $\mathrm{cm}$, and $(B)$ seed beetles (Callosobruchus), in which the presence and abundance of spines on the aedagus correlates with the thickness of the wall of the female's bursa copulatrix. (From Rönn et al. 2007; reprinted, with permission, from the National Academy of Sciences (C) 2007.)

sponses to copulation and male genital morphology can be varied, involving behavior, sensory systems, physiology, as well as morphology (also see Simmons 2013 for further discussion). These additional aspects of genital function can coevolve with male genital features. Therefore, studies that integrate copulatory behavior, functional morphology, and careful anatomical examination are needed before ruling out that features of female genitalia have not coevolved with male genitalia.

\section{Distinguishing between Mechanisms of Genital Coevolution}

Much effort has been spent trying to generalize predictions that allow distinction between evolutionary hypotheses of genital evolution (Arnqvist 1997; Eberhard 2004a,b, 2006, 2010a,b,
2011; Hosken and Stockley 2004). However, different selective mechanisms of genital coevolution are not necessarily mutually exclusive, and substantially different outcomes are expected through the interactions of different evolutionary mechanisms. They can act simultaneously or sequentially in evolutionary time, and in the same or separate genital traits (Arnqvist and Rowe 2005; Eberhard 2010b; Brennan and Prum 2012; Simmons 2013). In Figure 1, we illustrate how different mechanisms interact and overlap to produce genital evolution and coevolution. Each circle represents one mechanism of genital evolution: female choice, malemale competition, and natural selection.

Natural selection on genitalia can give rise to coevolution via: (1) adaptive size and morphological accommodation (i.e., in spider species in which tiny males have overly large genitalia to 
match the female), and (2) natural selection against hybridization (mechanical lock and key). Within female choice there are three potential mechanisms: Fisher-LK, good genes, and direct benefits. The Fisher-LK mechanism will occur when there is genetic variation for genital traits and genitally mediated preferences in the absence of natural selection on these preferences. Good genes and direct benefits can occur when female preferences (mediated by genital morphology) are under additional natural selection. This natural selection acts directly on female survival and fecundity, or indirectly on heritable genetic benefits to offspring. Just like any mating preference, all of these specific mechanisms can give rise to preference-trait coevolution, which is in this case nonantagonistic genital coevolution. In addition to good genes and direct benefits processes, the simultaneous action of female choice and natural selection against hybridization can give rise to sensory lock-and-key coevolution.

Male-male competition alone can give rise to genital evolution, but will not, by itself, produce genital coevolution between the sexes.

Sexual conflict occurs in the overlap between (1) male-male competition and natural selection on female survival and fecundity, or (2) male-male competition and female choice (Fig. 1, cross-hatched area) (Parker 2006; Brennan and Prum 2012). Sexual conflict can give rise to sexually antagonistic genital coevolution in various ways. Sexual conflict mediated by direct harm in the absence of female choice will result in SAC based on mitigating direct harm (e.g., in waterstriders). Sexual conflict mediated by female choice can produce SAC when female preferences are based on arbitrary traits (SACFisher), or when they are based on good genes (SAC-good genes), depending on the absence or presence of natural selection on the indirect, genetic benefits of mate choice, that males prevent females from obtaining (Fig. 1). For example, species in which males prevent the autonomous exercise of female choice, such as some waterfowl and Poeciliid fishes, show evidence of SAC. The complexity of the interactions between mechanisms illustrated here makes obvious why distinguishing these hypotheses is so difficult.
An economics approach that fully quantifies costs and benefits to male and female fitness of traits involved in coevolution has been suggested as a possible avenue to distinguish female choice and sexual conflict (Fricke et al. 2009; Simmons 2013). This approach may be possible with some insects in the laboratory, but it is not feasible in most wild, long-lived vertebrates. In addition, measuring current fitness could hide the success of female mitigating strategies against conflict, for example, if females succeed in preventing unwanted males from siring their offspring as waterfowl appear to do (Brennan and Prum 2012). Therefore, experimental manipulation to render putative traits involved in conflict ineffective, as suggested by Eberhard (2011) may be a better alternative, particularly in vertebrates.

Experimental modification of genital traits can be a powerful tool (Eberhard 2011). Experiments with males matched for size but differing only in one feature of genital morphology are needed, although finding enough variation in critical components can be very difficult (but see Okusaki and Sota 2014). Creating males and females with different genital genotypes using experimental evolution can reveal coevolutionary processes underlying genital traits. A recent experiment in seed beetles Callosobruchus maculatus generated phenotypic variation via both artificial selection and experimental ablation of spines and elegantly showed that longer spines, are beneficial to male fitness (Hotzy et al. 2012). Similarly, a recent study in Drosophila generated variation in male genitalia by creating introgressed lines between D. mauritiana and $D$. sechelia. They mated these males with varied morphologies to D. sechelia females, and showed that the greater the mismatch between male and female morphology, the greater the harm suffered by females (measured as scarring). This offers strong evidence that the coevolutionary process results from sexual conflict (Masly and Kamimura 2014).

Another possible avenue is to generate phenotypic diversity from phenotypic plasticity. Although previous work in insects showed that development of genitalia are canalized and show little evidence of plasticity (House 
and Simmons 2007), experiments in barnacles showed that genitalia can respond in a phenotypically plastic manner to wave action (Neufeld and Palmer 2008), and social environment, in which individuals grow shorter penises when colonies are more dense (Hoch 2009; Neufeld 2011). Similarly, we have found that some species of ducks have phenotypically plastic male genitalia in at least some species in response to their social environment (PLR Brennan, K Zyscowski, and RO Prum, unpubl.).

\section{EXAMPLES OF GENITAL COEVOLUTION}

\section{Insects}

Eberhard (2010b) and Simmons (2013) have provided comprehensive reviews of genital evolution in insects. Both agree that there is ample evidence that sexual selection is responsible for most genital diversity, but that sufficient data to discriminate among mechanisms are lacking in most species. However, Eberhard and Simmons disagree on their interpretation of the evidence in those species for which data exist. Further discussion of the many important points raised by both reviews is beyond the scope of this article but we encourage readers to refer to them for more details. Several examples of coevolution between male and female genital traits are summarized in Table 1 and Simmons (2013).

Experimental evolution and comparative studies combined with knowledge on the fitness effects of mating on females have shown genital coevolution occurs in dung beetles (Onthophagus sp.) via female choice (Simmons and GarcíaGonzález 2011) and seed beetles (Callosobruchus sp.) via sexual conflict (Cayetano et al. 2011). After 19 generations of sexual selection compared to enforced monogamy, the genital pits of female dung beetles (in which the parameres at the tip of the aedagus will anchor) become smaller and get closer and thus harder to reach, while the shape of their aedagus (external genitalia) changes in males (Simmons and García-González 2011). An interspecific phylogenetic study in dung beetles detected coevolution between the shape of the parameres and the female pygidial flap morphology in which the parameres fit into before intromission (Macagno et al. 2011). Female choice is likely the mechanism by which genitalia have diversified in dung beetles because there are no detectable fitness costs to promiscuity for females, and offspring have higher viability when females mate with multiple males (Simmons 2013).

In contrast, studies in seed beetles have supported a role for sexual conflict in genital evolution. As males in various species have evolved a more spiny aedagus that causes damage to the female reproductive tract, females have coevolved more substantial connective tissue within their copulatory ducts (Fig. 3B) (Rönn et al. 2007). After 21 generations of enforced monogamy in Callosobruchus macullatus, males evolved smaller spines on the tip of their aedagus, although no coevolutionary genital response in females was detected (Cayetano et al. 2011). Defensive traits may have a delayed evolutionary response, if they are not selected for reduction until enough reduction in the male damaging trait has been achieved (Cayetano et al. 2011). Alternatively, if the defensive trait is not too costly, there may not be selection to eliminate it. In the absence of other supporting information, the lack of female evolutionary response in seed beetles may be taken as evidence against a genetic correlation between male and female genitalia expected under SAC, so even experimental evolution may not necessarily provide complete answers when examining genital evolution. A genetic covariance exists between male damage and female susceptibility to damage exists in this species as evidenced by a full sib/half sib design (Gay et al. 2011). A recent comparative study in the Drosophila melanogaster species complex, revealed previously unknown internal and external female adaptations some of which appear to counteract or prevent the damage cause by male genital structures, therefore likely evolving by SAC, whereas others seeming to facilitate copulation, therefore evolving by female choice (Yassin and Orgogozo 2013).

\section{Arachnids}

Spider genitalia are extremely variable and show evidence of mechanical fit during copulation 
strongly supporting coevolution that may result from female choice for a mechanical fit that would proceed through good genes (Huber 1999; Eberhard and Huber 2010). However, it is unclear how females sense male genital features, when there is no evidence that female spider genitalia have any sensory structures (Eberhard and Huber 2010). There is no evidence to support mechanical lock and key or sexual conflict in this group. A recent study in harvestmen (Opiliones), provides comparative evidence that coevolution of genital structures is dynamic. Female sclerotized pregenital barriers evolve in concordance with the loss of male nuptial gifts to females, and subsequently evolving hardened penes (Burns et al. 2013). Therefore, sexual conflict over male investment and fertilization may be important in this group (Burns et al. 2013). The evolved loss of nuptial gifts appears to be associated with changes in the length of the mating season, providing a direct link to ecology and life-history evolution that is typically lacking in genital evolution studies.

Fish

Poeciliids are becoming an excellent model to study of genital coevolution. Here we summarize some key aspects of their biology from Greven (2005) and Langerhans (2011). Unlike most teleost fishes with external fertilization, male poeciliids have evolved a novel genital intromittent organ or gonopodium modified from anal fin rays. Poeciliids have both elaborate sexually dimorphic coloration patterns and display behaviors that are subject to female mate choice, and males in 38\% of species display but also pursue forced copulations. In $58 \%$ of poeciliid species, males do not display to females but only coerce copulations. Interspecies comparisons show that species with longer gonopodia exhibit reduced courtship displays (Greven 2005; Martin et al. 2010). The tip of the gonopodium can have structures used for insertion, grasping, stabilizing, and sensing, but whether there is a relationship between gonopodium length and tip elaboration remains unclear (Greven 2005). When hooks are present, males can get stuck inside the female and cause damage to her reproductive tract (Greven 2005).

Evidence of genital coevolution at the population level has been provided in guppies ( $\mathrm{Po}$ ecilia reticulata). Male guppies routinely force females to copulate, and gonopodium length is associated with success in forced copulations (Kelly et al. 2000). Forced copulations are costly to females (Magurran and Seghers 1994). An intraspecific study examining different guppy populations in which gonopodium length and shape is known to differ according to predation risk, showed that males with longer gonopodium were more successful at achieving forced copulations, while males with shorter gonopodium tips transferred more sperm into females (Evans et al. 2011). In high predation populations in which males have shorter gonopodium tips, females have wider oviducts than fish from low predation populations, suggesting that coevolution is taking place between male and female genitalia (Evans et al. 2011). Quantitative trait loci of genital traits between these differing populations have provided evidence of genetic covariation in genital traits, and high additive genetic variance, that support a critical prediction of coevolutionary processes under both female choice and sexual conflict (Evans et al. 2013). A recent experiment showed that the claw at the end of the gonopodium, increases sperm transfer only when females are nonreceptive, supporting its potential role in sexual conflict (Kwan et al. 2013). Overall, there is strong evidence of sexual conflict over copulation in guppies, and therefore genital coevolution in this species likely proceeds by sexual conflict.

\section{Squamates}

Male squamates have paired intromittent organs known as hemipenes that are often species specific. Female genitalia in snakes have been shown to vary at least among families (e.g., Siegel et al. 2011). Eversion of one hemipenis takes place into the female cloaca and vaginal tract. Not much work has been performed specifically on genital coevolution in this group, although shape correspondence indicative of coevolution seems 
P.L.R. Brennan and R.O. Prum

widespread (Pope 1941; Edgren 1953; Pisani 1976; Böhme and Ziegler 2009; King et al. 2009).

In at least some species, this close shape fit has been used to suggest a coevolutionary process that could result from female choice (Böhme and Ziegler 2009), sexual conflict (King et al. 2009), or natural selection lockand-key mechanisms (Pope 1941). Our own observations in 12 species of snakes including natricine and non-natricines, and two lizards have also revealed shape correspondence (Fig. 4A) (PLR Brennan, K Zyscowski, and RO Prum, unpubl.). However, shape correspondence is apparently not universal in snakes (Siegel et al. 2011). Similar to the dung beetles, there seems to be correspondence between how spiny the hemipenes are, and the thickness of the vaginal
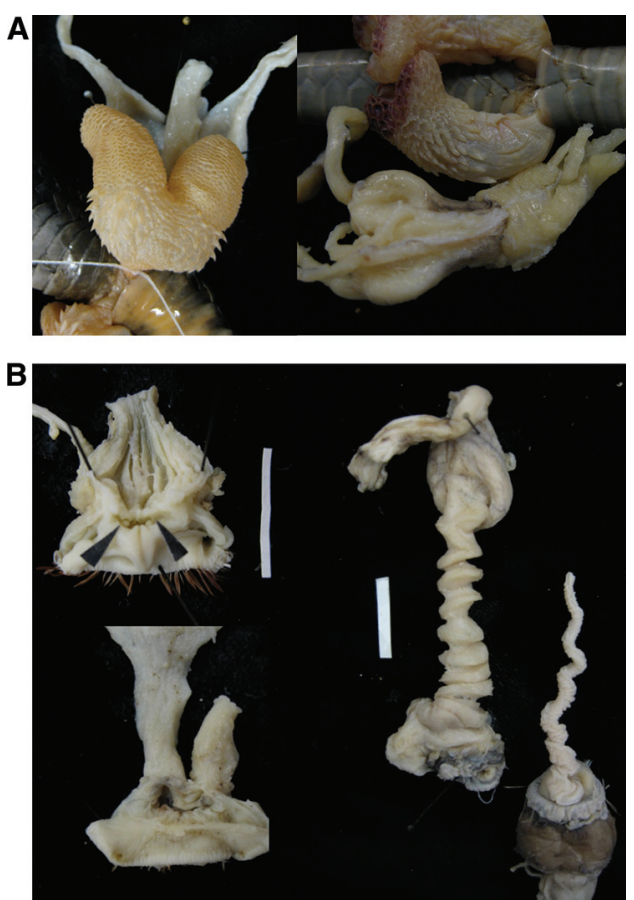

Figure 4. Genital coevolution. (A) Snakes, in which the shape of the inflated male hemipenes corresponds with the shape of the female vagina (Crotalis horridus and Coluber constrictor), and (B) tinamous species without a penis have a simple vagina (Crypturellus undulatus male cloaca with nonintromittent penis and female on the left); the presence of a long penis is associated with an accordion-like vagina (Tinamus major on the right). Scale bars, $2 \mathrm{~cm}$. wall in two species of Asiatic pit vipers (Pope 1941). This is likely a widespread phenomenon in squamates as many species have spiny hemipenes that leave imprints inside the female after copulation (Pope 1941).

\section{Birds}

Genital evolution in birds is certainly more complex than previously appreciated (Brennan 2013), and we recently discovered genital coevolution in tinamous (Family Tinamidae), a basal family of birds, which is within the ratites (Fig. 4B) (PLR Brennan, K Zyscowski, and RO Prum, unpubl.). Some tinamou species have long intromittent penises, whereas others have a reduced nonintromittent penis (i.e., Tinamus vs. Crypturellus) (Brennan et al. 2008). In species with a nonintromittent penis, female vaginas are a simple tube, whereas in species with an intromittent penis, the female vagina is folded like an accordion (Fig. 4B).

Genital coevolution in tinamous could have evolved by: (1) male-male competition and natural selection, or (2) female choice. Female tinamous are often promiscuous, so there is opportunity for sperm competition and female choice based on genital size and shape. Male tinamous could benefit from having a longer penis to deposit their sperm as close to the sperm storage tubules as possible. If a long penis is favored via male-male competition, then there might be natural selection on females to elongate their genitalia to allow for mechanical fit during copulation. Alternatively, tinamou penis size could also coevolve with vaginal morphology through female choice for greater copulatory stimulation. Female vaginal morphology could provide a morphological mechanism to distinguish among males with different genital lengths. The derived shift to monogamy in Crypturellus may have reduced selection on males to insure sperm storage, or eliminated the opportunity for female choice based on male genital features, leading to a reduction in penis length. The potential egg-laying cost to a long folded vagina may be enough to select against female genital elaboration, as tinamous lay some of the largest eggs for any given body size in birds (Davies 2002). 


\section{Mammals}

Among placental mammals, insectivores, rodents, carnivores, bats, and primates generally have a penis bone known as the baculum, or os penis. The baculum is known to be morphologically diverse and subject to sexual selection at least in some groups (Ramm 2007). However, no studies have investigated effects of baculum shape on female genital morphology predicted by several hypotheses of baculum evolution including vaginal friction, induced ovulation, and sperm transfer during prolonged copulation (Patterson and Thaeler 1982; Larivière and Ferguson 2002; Dixson 2012).

In mice, baculum morphology appears to be associated with higher male fitness (Stockley et al. 2013), while experimental evolution studies have shown that mice evolving under high sexual selection (compared to enforced monogamy) change the shape although not the size of their baculum (Simmons and Firman 2014). These changes may be associated with higher mechanical stimulation of females to enhance litter size (Simmons and Firman 2014), although the mechanism by which baculum shape changes affect male fitness remains unknown, and will require an examination of females to determine how they can sense copulatory stimuli.

Primates have highly variable penile morphology. The specialization and characteristics of the primate penis are consistent with sexual selection hypotheses, in that penis length, tip elaboration and the presence of penile spines, are associated with multimale, multifemale groups, and dispersed mating systems in which females are promiscuous (Dixson 2012). In most primates with long bacula, the tip of the bone projects from the tip of the penis to contact the entrance of the cervix, facilitating sperm transport into the uterus (Dixson 2012). This suggests that there should be some coevolution in length between the penis and the vagina. However, unlike the case of penis length, a preliminary analysis of vaginal length found no correlation with mating system (Dixson 2012). A weak relationship seems to exist between the presence of female sexual swellings and long penises. For example, female sexual swellings can increase the distance to the cervical os up to $50 \%$ in chimpanzees (Dixson 2012), so a longer penis would be required to contact the female cervix during estrous, and this may explain the long filiform penis of male chimps (Dixson 2012).

In humans, MRI of individuals during coitus in the missionary position showed very close fit in shape, but significantly also that the anterior wall of the vagina lengthened by $1 \mathrm{~cm}$ in the preorgasmic phase (Schultz et al. 1999), underscoring the importance of examining copulation itself to understand how male and female genitalia fit together. Even though precopulatory female choice may play a role in penis length in humans (Mautz et al. 2013), whether copulatory female choice for genital features also takes place is unknown. The female vagina is densely innervated, particularly its anterior and posterior walls (Hilleges et al. 1995), and clearly this sensory ability can allow females to sense male penis size. Although previous studies have shown strong variation in genitalia among human ethnic groups (vagina: Pendergrass et al. 2000; penis: data by country compiled in Khan et al. 2012), there has been no rigorous effort to study human genital size coevolution with comparative analyses using standardized methods.

\section{CONCLUSION}

Evidence suggests that genital coevolution is widespread, and that both sexual conflict and female choice are commonly supported as the main coevolutionary mechanisms. Investigation of the mechanisms of genital coevolution and sexual conflict requires understanding the independent and co-occurring action of natural selection, female choice, and male-male competition. Genital coevolution can be inferred by comparative studies of closely related species or populations, as well as by microevolutionary studies that experimentally measure the fitness effects of rendering genital features ineffective. Experimental evolution can uncover the selective pressures responsible for genital evolution and establish whether changes in genital features in one sex result in changes in the other 
sex with fitness consequences. However, lack of evidence for coevolutionary responses in female defensive traits does not necessarily suggest that coevolution has not taken place, but merely that maintenance of female defensive traits may not be too costly. However, lack of understanding of functional morphology of genitalia during copulation, and copulatory behavior, as well as scarcity of quantitative studies that examine female genital variation, hinder further progress in our understanding of the mechanisms responsible for coevolution with few exceptions in model systems.

\section{ACKNOWLEDGMENTS}

P.L.R.B. is partly supported by National Science Foundation (NSF) grant IOS 0920344 while some of the work in this article was being conducted. We thank Teri Orr for helpful discussions during the preparation of this manuscript.

\section{REFERENCES}

Ah-King M, Barron AB, Herberstein ME. 2014. Genital evolution: Why are females still understudied? PLoS Biol 12: e1001851.

Andersson MB. 1994. Sexual selection. Princeton University Press, Princeton, NJ.

Arnqvist G. 1997. The evolution of animal genitalia: Distinguishing between hypothesis by single species studies. Biol J Linn Soc Lond 60: 365-379.

Arnqvist G, Rowe L. 2002. Correlated evolution of male and female morphologies in water striders. Evolution (NY) 56: 936-947.

Arnqvist G, Rowe L. 2005. Sexual conflict. Princeton University Press, Princeton, NJ.

Augee ML, Gooden BA, Musser A. 2006. Echidna: Extraordinary egg-laying mammal. CSIRO, Collingwood, Australia.

Bedford JM, Mock OB, Goodman SM. 2004. Novelties of conception in insectivorous mammals (Lipotyphla), particularly shrews. Biol Rev 79: 891-909.

Böhme W, Ziegler T. 2009. A review of iguanian and anguimorph lizard genitalia (Squamata: Chamaeleonidae; Varanoidea, Shinisauridae, Xenosauridae, Anguidae) and their phylogenetic significance: Comparisons with molecular data sets. J Zool Syst Evol Res 47: 189-202.

Bonet S, Casas I, Holt WV, Yeste M. 2013. Boar reproduction: Fundamentals and new biotechnological trends. Springer, Berlin.

Breed WG, Leigh CM, Speight N. 2013. Coevolution of the male and female reproductive tracts in an old endemic murine rodent of Australia. J Zool 289: 94-100.
Brennan PLR. 2013. Genital evolution: Cock-a-doodledon't. Curr Biol 23: R523-R525.

Brennan PLR, Prum R. 2012. Sexual conflict in the narrow sense: New insights from waterfowl biology. Phil Trans $R$ Soc 367: 2324-2338.

Brennan PLR, Prum RO, McCracken KG, Sorenson MD, Wilson RE, Birkhead TR. 2007. Coevolution of male and female genital morphology in waterfowl. PLOS ONE 25: e418.

Brennan PLR, Birkhead T, Zyskowski K, Van der Waag J, Prum RO. 2008. Independent evolutionary reductions of the phallus in basal birds. J Avian Biol 39: 487-492.

Brennan PLR, Clark C, Prum R. 2010. Explosive eversion and functional morphology of waterfowl penis supports sexual conflict in genitalia. Proc Biol Sci 277: 1309-1314.

Briceño RD, Eberhard WG. 2009a. Experimental modifications of male genitalia induce cryptic female choice against the male in a tsetse fly. J Evol Biol 22: 1516-1525.

Briceño RD, Eberhard WG. 2009b. Experimental demonstration of possible cryptic female choice on male tsetse fly genitalia. J Insect Physiol 55: 989-996.

Burns MM, Hedin M, Shultz JW. 2013. Comparative analyses of reproductive structures in harvestmen Opiliones reveal multiple transitions from courtship to precopulatory antagonism. PLoS ONE 8: e66767.

Carayon J. 1966. Traumatic insemination and the paragenital system. In Monograph of Cimicidae (Hemiptera, Heteroptera), pp. 81-166. Entomological Society of America, College Park, MD.

Cayetano L, Maklakov AA, Brooks RC, Bonduriansky R. 2011. Evolution of male and female genitalia following release from sexual selection. Evolution (NY) 65: 21712183.

Chapman T, Arnqvist G, Bangham J, Rowe L. 2003. Sexual conflict. Trends Ecol Evol 181: 41-47.

Darwin C. 1871. The descent of man and selection in relation to sex (reprinted in 1959). Modern Library, New York.

Davies SJJF. 2002. Ratites and tinamous, p. 310. Oxford University Press, Oxford.

Defour L. 1844. Anatomie generale des Dipteres [General anatomy of the Dipteridae]. Ann Sci Nat 1: 244-264.

Dixson AF. 2012. Primate sexuality: Comparative studies of the prosimians, monkeys, apes, and humans. Oxford University Press, Oxford.

East ML, Hofer H, Wickler W. 1993. The erect "penis" is a flag of submission in a female-dominated society: Greetings in Serengeti spotted hyenas. Behav Ecol Sociobiol 336: 355-370.

Eberhard WG. 1985. Sexual selection and animal genitalia. Harvard University Press, Cambridge, MA.

Eberhard WG. 1996. Female control: Sexual selection by cryptic female choice. Princeton University Press, Princeton, NJ.

Eberhard WG. 2004a. Male-female conflict and genitalia: Failure to confirm predictions in insects and spiders. Biol Rev 79: 121-186.

Eberhard WG. 2004b. Rapid divergent evolution of sexual morphology: Comparative tests of antagonistic coevolution and traditional female choice. Evolution (NY) 58: 1947-1970. 
Eberhard W. 2006. Sexually antagonistic coevolution in insects is associated with only limited morphological diversity. J Evol Biol 19: 657-681.

Eberhard W. 2010a. Evolution of genitalia: Theories, evidence, and new directions. Genetica 138: 5-18.

Eberhard W. 2010b. Rapid divergent evolution of genitalia: Theory and data updated. In The evolution of primary sexual characters in animals, pp. 40-78. Oxford University Press, Oxford.

Eberhard W. 2011. Experiments with genitalia: A commentary. TREE 26: 17-21.

Eberhard W, Huber BA. 2010. Spider genitalia: Precise maneuvers with a numb structure in a complex lock. In The evolution of primary sexual characters in animals, pp. 249-284. Oxford University Press, Oxford.

Eberhard WG, Ramirez N. 2004. Functional morphology of the male genitalia of four species of Drosophila: Failure to confirm both lock and key and male-female conflict. Annls Entomol Soc Am 97: 1007-1017.

Eberhard WG, Huber BA, Rodriguez RLS, Briceño RD, Salas I, Rodriguez V. 1998. One size fits all? Relationships between the size and degree of variation in genitalia and other body parts in twenty species of insects and spiders. Evolution (NY) 52: 415-431.

Edgren RA. 1953. Copulatory adjustment in snakes and its evolutionary implications. Copeia 1953: 162-164.

Evans JP, Gasparini C, Holwell GI, Ramnarine IW, Pitcher TE, Pilastro A. 2011. Intraspecific evidence from guppies for correlated patterns of male and female genital trait diversification. Proc Biol Sci 278: 2611-2620.

Evans JP, van Lieshout E, Gasparini C. 2013. Quantitative genetic insights into the coevolutionary dynamics of male and female genitalia. Proc Biol Sci 280: 1763-1767.

Fooden J. 1967. Complementary specialization of male and female reproductive structures in the bear macaque, Macaca arctoides. Nature 214: 939-941.

Forero D, Berniker L, Weirauch C. 2013. Phylogeny and character evolution in the bee-assassins (Insecta: Heteroptera: Reduviidae). Mol Phylogenet Evol 66: 283-302.

Fricke C, Perry J, Chapman T, Rowe L. 2009. The conditional economics of sexual conflict. Biol Lett 5: 671-674.

Friesen C, Uhrig EJ, Squire MJ, Mason R, Brennan PLR. 2014. Sexual conflict over mating in red-sided Garter snakes Thamnophis sirtalis as evidenced by experimental manipulation of genitalia. Proc Biol Sci 281: 20132694.

Gay L, Brown E, Tregenza T, Pincheira-Donoso D, Eady PE, Vasudev R, Hunt J, Hosken DJ. 2011. The genetic architecture of sexual conflict: Male harm and female resistance in Callosobruchus maculatus. J Evol Biol 24: $449-456$.

Greven H. 2005. Structural and behavioral traits associated with sperm transfer in the Poeciliinae. In Viviparous fishes (ed. Grier HJ, Uribe MC), pp. 147-165. New Life, Homestead, FL.

Hilleges M, Falconer C, EkmaňOrdeberg G, Johanson O. 1995. Innervation of the human vaginal mucosa as revealed by PGP 9.5 immunohistochemistry. Acta Anat 153: 119 .

Hoch JM. 2009. Adaptive plasticity of the penis in a simultaneous hermaphrodite. Evolution (NY) 63: 1946-1953.
Hosken DJ, Stockley P. 2004. Sexual selection and genital evolution. Trend Ecol Evol 192: 87-93.

Hotzy C, Polak M, Rönn JL, Arnqvist G. 2012. Phenotypic engineering unveils the function of genital morphology. Curr Biol 22: 2258-2261.

House CM, Simmons LW. 2007. No evidence for conditiondependent expression of male genitalia in the dung beetle Onthophagus taurus. J Evol Biol 20: 1322-1332.

House CM, Lewis Z, Hodgson DJ, Wedell N, Sharma MD, Hunt J, Hosken DJ. 2013. Sexual and natural selection both influence male genital evolution. PloS ONE 8: e63807.

Huber BA. 1999. Sexual selection in pholcid spiders (Araneae, Pholcidae): Artful chelicerae and forceful genitalia. J Arachnol 27: 135-141.

Ilango K, Lane RP. 2000. Coadaptation of male aedeagal filaments and female spermathecal ducts of the old world phlebotomine sand flies. J Med Entomol 37: 653-659.

Jagadeeshan S, Singh RS. 2006. A time-sequence functional analysis of mating behaviour and genital coupling in Drosophila: Role of cryptic female choice and male sexdrive in the evolution of male genitalia. J Evol Biol 19: 1058-1070.

Johnston SD, Smith B, Pyne M, Stenzel D, Holt WV. 2007. One-sided ejaculation of echidna sperm bundles. Am Nat 1706: E162-E164.

Kameda Y, Kawakita A, Kato M. 2009. Reproductive character displacement in genital morphology in Satsuma land snails. Am Nat 173: 689-697.

Kamimura Y. 2012. Correlated evolutionary changes in Drosophila female genitalia reduce the possible infection risk caused by male copulatory wounding. Behav Ecol Sociobiol 66: 1107-1114.

Kelly CD, Godin JG, Abdallah G. 2000. Geographic variation in the male intromittent organ of the Trinidadian guppy Poecilia reticulata. Can J Zool 78: 1674-1680.

Khan S, Somani B, Lam W, Donat R. 2012. Establishing a reference range for penile length in Caucasian British men: A prospective study of 609 men. BJU Int 1095: $740-744$.

Kinahan AA, Bennett NC, O’Riain MJ, Hart L, Bateman PW. 2007. Size matters: Genital allometry in an African molerat (Family: Bathyergidae). Evol Ecol 21: 201-213.

King RB, Jadin RC, Grue M, Walley HD. 2009. Behavioral correlates with hemipenis morphology in New World natricine snakes. Biol J Linn Soc Lond 98: 110-120.

Kirkpatrick M, Ryan MJ. 1991. The evolution of mating preferences and the paradox of the lek. Nature 350: $33-38$.

Köhler J, Hahn M, Köhler G. 2012. Divergent evolution of hemipenial morphology in two cryptic species of mainland anoles related to Anolis polylepis. Salamandra 48: $1-11$.

Kotrba M, Huber J, Feijen HR. 2014. Coevolution of male and female genitalia in stalk-eyed flies (Diptera: Diopsidae). Org Divers Evol 14: 187-201.

Kuntner M, Coddington JA, Schneider JM. 2009. Intersexual arms race? Genital coevolution in Nephilid spiders (Araneae, Nephilidae). Evolution (NY) 63: 1451-1463. 
P.L.R. Brennan and R.O. Prum

Kwan L, Cheng YY, Rodd FH, Rowe L. 2013. Sexual conflict and the function of genitalic claws in guppies Poecilia reticulata. Biol Lett 95: 20130267.

Langerhans RB. 2011. Genital evolution. In Ecology and evolution of poeciliid fishes, pp. 228-240. University of Chicago Press, Chicago.

Larivière S, Ferguson SH. 2002. On the evolution of the mammalian baculum: Vaginal friction, prolonged intromission or induced ovulation? Mamm Rev 32: 283-294.

Lautenschlager AD, Brandis D, Storch V. 2010. Morphology and function of the reproductive system of representatives of the genus Uca. J Morphology 271: 1281-1299.

Macagno AL, Pizzo A, Parzer HF, Palestrini C, Rolando A, Moczek AP. 2011. Shape-but not size-codivergence between male and female copulatory structures in onthophagus beetles. PloS ONE 6: e28893.

Magurran AE, Seghers BH. 1994. A cost of sexual harassment in the guppy, Poecilia reticulata. Proc $R$ Soc B 258: 89-92.

Martin SB, Albert JS, Leberg PL. 2010. The evolution of the poeciliid gonopodium: Integrating morphological and behavioral traits. In Viviparous fishes II (ed. Uribe M, Grier H). New Life, Homestead, FL.

Masly JP. 2012. 170 years of "lock-and-key": Genital morphology and reproductive isolation. Int J Evol Biol 2012: 247352.

Masly JP, Kamimura Y. 2014. Asymmetric mismatch in strain-specific genital morphology causes increased harm to Drosophila females. Evolution (NY) doi: 10.1111/evo.12436.

Matthews LH. 1950. Reproduction in the basking shark, Cetorhinus maximus (Gunner). Phil Trans R Soc B 234: 247-316.

Mautz BS, Wong BBM, Peters RA, Jennions MD. 2013. Penis size interacts with body shape and height to influence male attractiveness. Proc Natl Acad Sci 110: 6925-6930.

McPeek MA, Shen L, Farid H. 2009. The correlated evolution of three-dimensional reproductive structures between male and female damselflies. Evolution (NY) 63: 73-83.

Mikkola K. 1992. Evidence for lock-and-key mechanisms in the internal genitalia of the Apamea moths (Lepidoptera Noctuidae). Syst Entomol, 17: 145-153.

Morrow EH, Arnqvist G. 2003. Costly traumatic insemination and a female counter-adaptation in bed bugs. Proc Biol Sci 270: 2377-2381.

Mutanen M, Kaitala A, Mönkkönen M. 2006. Genital variation within and between three closely related Euxoa moth species: Testing the lock-and-key hypothesis. $J$ Zool 2682: 109-119.

Neufeld CJ. 2011. Modular phenotypic plasticity: Divergent responses of barnacle penis and feeding leg form to variation in density and wave-exposure. J Exp Zool B Mol Dev Evol 316: 254-262.

Neufeld CJ, Palmer AR. 2008. Precisely proportioned: Intertidal barnacles alter penis form to suit coastal wave action. Proc Bio Sci 275: 1081-1087.

Okuzaki Y, Sota T. 2014. How the length of genital parts affects copulation performance in a carabid beetle: Implications for correlated genital evolution between the sexes. J Evol Biol 27: 565-574.
Parker GA. 2006. Sexual conflict over mating and fertilization: An overview. Phil Trans R Soc B 361: 235-259.

Patterson BD, Thaeler CS Jr. 1982. The mammalian baculum: Hypotheses on the nature of bacular variability. $J$ Mammal 1-15.

Pendergrass PB, Reeves CA, Belovicz MW, Molter DJ, White JH. 2000. Comparison of vaginal shapes in Afro-American, Caucasian and Hispanic women as seen with vinyl polysiloxane casting. Gynecol Obstet Invest 501: 54-59.

Pereti AV. 2010. An ancient indirect sex model: Single and mixed patterns in the evolution of scorpion genitalia. In The evolution of primary sexual characters in animals (ed. Leonard JL, Córdoba-Aguilar A). Oxford University Press, Oxford.

Perry JC, Rowe L. 2012. Sexual conflict and antagonistic coevolution across water strider populations. Evolution (NY) 66: 544-557.

Pisani GR. 1976. Comments on the courtship and mating mechanics of Thamnophis (Reptilia, Serpentes, Colubridae). J Herpetol 10: 139-142.

Polihronakis M. 2006. Morphometric analysis of intraspecific shape variation in male and female genitalia of Phyllophaga hirticula (Coleoptera: Scarabaeidae: Melolonthinae). Ann Entomol Soc Am 991: 144-150.

Pope CH. 1941. Copulatory adjustment in snakes. Field Mus Nat Hist, Zool Ser 24: 249-252.

Prum RO. 2010. The Lande-Kirkpatrick mechanism is the null model of evolution by intersexual selection: Implications for meaning, honesty, and design in intersexual signals. Evolution (NY) 64: 3085-3100.

Puniamoorthy N, Kotrba M, Meier R. 2010. Unlocking the "Black box": Internal female genitalia in Sepsidae Diptera evolve fast and are species-specific. BMC Evol Biol 101: 275.

Ramm SA. 2007. Sexual selection and genital evolution in mammals: A phylogenetic analysis of baculum length. Am Nat 169: 360-369.

Ramos M, Coddingtion JA, Christenson TE, Irschick DJ. 2005. Have male and female genitalia coevolved? A phylogenetic analysis of genitalic morphology and sexual size dimorphism in web-building spiders (Araneae: Araneoidea). Evolution (NY) 59: 1989-1999.

Renfree M. 1987. Reproductive physiology of marsupials. Cambridge University Press, Cambridge.

Robertson HM, Paterson HE. 1982. Mate recognition and mechanical isolation in Enallagma damselflies (Odonata: Coenagrionidae). Evolution (NY) 243-250.

Rönn J, Katvala M, Arnqvist G. 2007. Coevolution between harmful male genitalia and female resistance in seed beetles. Proc Natl Acad Sci 104: 10921-10925.

Sánchez V, Cordero C. 2014. Sexual coevolution of spermatophore envelopes and female genital traits in butterflies: Evidence of male coercion? PeerJ 2: e247.

Sasabe M, Takami Y, Sota T. 2010. QTL for the species-specific male and female genital morphologies in Ohomopterus ground beetles. Mol Ecol 19: 5231-5239.

Sauer J, Hausdorf B. 2009. Sexual selection is involved in speciation in a land snail radiation on Crete. Evolution 63: 2535-2546.

Schultz WW, Van Andel P, Sabelis I, Mooyaart E. 1999. Magnetic resonance imaging of male and female geni- 
tals during coitus and female sexual arousal. BMJ 319: 1596-1600.

Shapiro AM, Porter AH. 1989. The lock-and-key hypothesis: Evolutionary and biosystematic interpretation of insect genitalia. Ann Rev Entomol 34: 231-245.

Showalter I, Todd B, Brennan PLR. 2013. Intraspecific and interspecific variation of the vagina in two species of water snakes. Biol J Linn Soc Lond 111: 183-191.

Siegel DS, Miralles A, Trauth SE, Aldridge RD. 2011 The phylogenetic distribution and morphological variation of the "pouch" in female snakes. Acta Zool 93: 400408.

Simmons LW. 2013. Sexual selection and genital evolution Aust J Entomol 53: 1-17.

Simmons LW, Firman RC. 2014. Experimental evidence for the evolution of the mammalian baculum by sexual selection. Evolution (NY) 68: 276-283.

Simmons LW, García-González F. 2011. Experimental coevolution of male and female genital morphology. Nat Commun 2: 374-377.

Simmons LW, House CM, Hunt J, García-González F. 2009. Evolutionary response to sexual selection in male genital morphology. Curr Biol 1917: 1442-1446.

Sota T, Kubota K. 1998. Genital lock-and-key as a selective agent against hybridization. Evolution (NY) 52: $1507-$ 1513.
Sota T, Tanabe T. 2010. Multiple speciation events in an arthropod with divergent evolution in sexual morphology. Proc R Soc B 277: 689 .

Stockley P, Ramm SA, Sherborne AL, Thom MDF, Paterson S, Hurst JL. 2013. Baculum morphology predicts reproductive success of male house mice under sexual selection. BMC Biol 11: 66 .

Tanabe T, Sota T. 2008. Complex copulatory behavior and the proximate effect of genital and body size differences on mechanical reproductive isolation in the millipede genus Parafontaria. Am Nat 1715: 692-699.

Tatarnic NJ, Cassis G. 2010. Sexual coevolution in the traumatically inseminating plant bug genus Coridromius. J Evol Biol 23: 1321-1326.

Wojcieszek JM, Simmons LW. 2012. Micro-CT scanning provides insight into the functional morphology of millipede genitalia. J Zool 287: 91-95.

Wojcieszek JM, Simmons LW. 2013. Divergence in genital morphology may contribute to mechanical reproductive isolation in a millipede. Ecol Evol 32: 334-343.

Yassin A, Orgogozo V. 2013. Coevolution between male and female genitalia in the Drosophila melanogaster species subgroup. PloS ONE 82: e57158.

Yoshizawa K, Ferreira RL, Kamimura Y, Lienhard C. 2014. Female penis, male vagina, and their correlated evolution in a cave insect. Curr Biol 24: 1006-1010. 


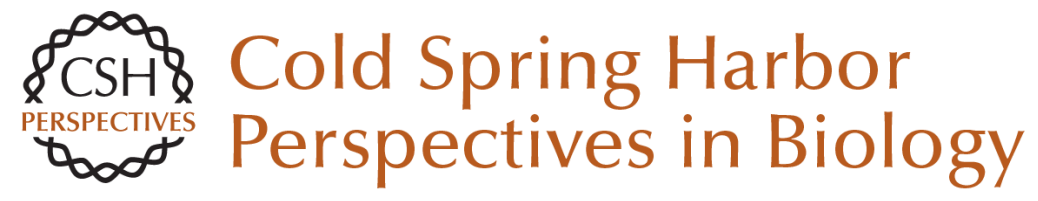

\title{
Mechanisms and Evidence of Genital Coevolution: The Roles of Natural Selection, Mate Choice, and Sexual Conflict
}

\author{
Patricia L.R. Brennan and Richard O. Prum \\ Cold Spring Harb Perspect Biol 2015; doi: 10.1101/cshperspect.a017749
}

\section{Subject Collection The Genetics and Biology of Sexual Conflict}

Mechanisms and Evidence of Genital

Coevolution: The Roles of Natural Selection, Mate Choice, and Sexual Conflict

Patricia L.R. Brennan and Richard O. Prum

The Evolution of Sexually Antagonistic

Phenotypes

Jennifer C. Perry and Locke Rowe

Reproductive Parasitism: Maternally Inherited Symbionts in a Biparental World Gregory D.D. Hurst and Crystal L. Frost

Sex-Biased Gene Expression and Sexual Conflict throughout Development

Fiona C. Ingleby, Ilona Flis and Edward H. Morrow

Human Homosexuality: A Paradigmatic Arena for Sexually Antagonistic Selection?

Andrea Camperio Ciani, Umberto Battaglia and Giovanni Zanzotto

Sexual Conflict Arising from Extrapair Matings in Birds

Alexis S. Chaine, Robert Montgomerie and Bruce E. Lyon

Sexual Conflict and Seminal Fluid Proteins: A Dynamic Landscape of Sexual Interactions Laura K. Sirot, Alex Wong, Tracey Chapman, et al.

Conflict on the Sex Chromosomes: Cause, Effect, and Complexity

Judith E. Mank, David J. Hosken and Nina Wedell
Infanticide as Sexual Conflict: Coevolution of

Male Strategies and Female Counterstrategies Ryne A. Palombit

Copulatory Wounding and Traumatic Insemination

Klaus Reinhardt, Nils Anthes and Rolanda Lange

Sexual Conflict in Hermaphrodites Lukas Schärer, Tim Janicke and Steven A. Ramm

Sexual Conflict and Sperm Competition Dominic A. Edward, Paula Stockley and David J. Hosken

Sexually Antagonistic Zygotic Drive: A New Form of Genetic Conflict between the Sex

Chromosomes

Urban Friberg and William R. Rice

Sex Chromosome Drive

Quentin Helleu, Pierre R. Gérard and Catherine Montchamp-Moreau

Is Sexual Conflict an "Engine of Speciation"? Sergey Gavrilets

Sexual Cannibalism as a Manifestation of Sexual Conflict Jutta M. Schneider

For additional articles in this collection, see http://cshperspectives.cshlp.org/cgi/collection/

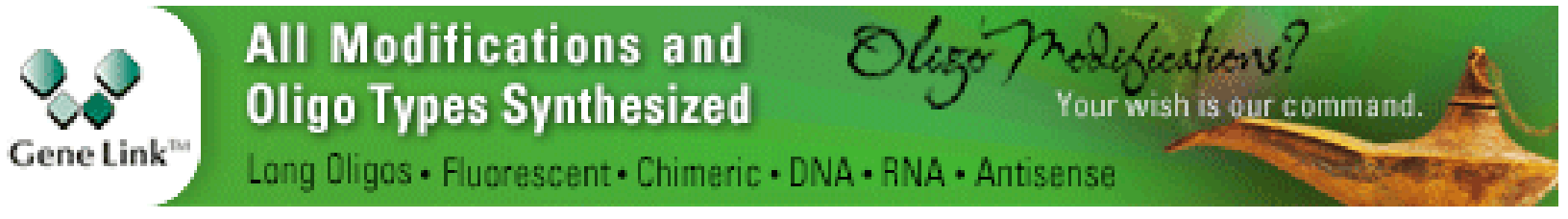


For additional articles in this collection, see http://cshperspectives.cshlp.org/cgi/collection/

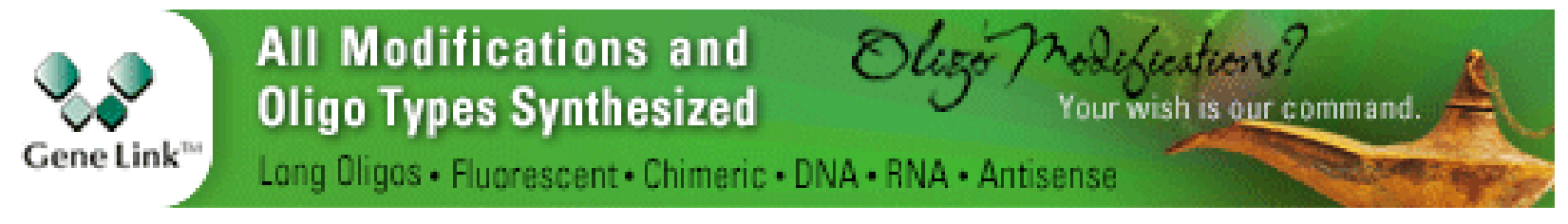

Copyright @ 2015 Cold Spring Harbor Laboratory Press; all rights reserved 